\title{
PERHITUNGAN PATHLOSS TEKNOLOGI 4G LONG TERM EVOLUTION (LTE)
}

\author{
Maria Ulfah \\ Jurusan Teknik Elektronika, Politeknik Negeri Balikpapan \\ maria.ulfah@poltekba.ac.id
}

\begin{abstract}
Wave propagation through an air transmission medium is important for the smooth mobile communications, because the signal is distributed by the air transmission medium to be received by the recipient is affected by the contours of the earth, media reflection, the obstacle and the distance and the possibilities that can not be predicted appearance and inhibit the signal transmission process is in progress.

Important to take into account pathloss signals that occur along the transmission line, because it affects the quality of the signal to be received. In determining the loss signal propagation model is used in accordance with the COST 231 for $1800 \mathrm{MHz} 4 \mathrm{G}$ LTE frequency.

In this study calculated pathloss signal 4G LTE with distance variation antena transmitter (E node B) to the receiver (mobile station) is $1 \mathrm{~km}, 5 \mathrm{~km}, 10 \mathrm{~km}, 15 \mathrm{~km}, 20 \mathrm{~km}$, with a height of antena transmitter 24 meter. From the results of the calculation, the greater the distance between the transmitter antena towards the receiver pathloss value is the greater of $138.8853 \mathrm{Db}$ to $175.4915 \mathrm{~dB}$. Meanwhile, if the receiver antena height is enlarged to the distance d between the eNodeB with MS remain the pathloss value to decrease. The greater the value of pathloss the received signal quality will decline and otherwise
\end{abstract}

Keywords: 4G LTE, pathloss, model propagasi COST 231

\section{INTISARI}

Propagasi gelombang melalui media transmisi udara sangatlah berperan penting bagi kelancaran komunikasi seluler, karena sinyal yang disalurkan oleh media transmisi udara yang akan diterima oleh penerima dipengaruhi oleh kontur bumi, media pantulan, penghalang (obstacle) serta jarak dan kemungkinan-kemungkinan yang tidak dapat diprediksi kemunculannya dan menghambat proses transmisi sinyal yang berlangsung.

Penting dalam memperhitungkan rugi-rugi (pathloss) sinyal yang terjadi disepanjang saluran transmisi, karena mempengaruhi kualitas sinyal yang akan diterima. Dalam menentukan rugi-rugi sinyal digunakan model propagasi COST 231 karena sesuai dengan frekuensi 4G LTE yaitu $1800 \mathrm{MHz}$.

Dalam penelitian ini dihitung rugi-rugi (pathloss) sinyal 4G LTE dengan variasi jarak antena pemancar (E node B) terhadap penerima (mobile station) yaitu $1 \mathrm{~km}, 5 \mathrm{~km}, 10 \mathrm{~km}, 15 \mathrm{~km}, 20 \mathrm{~km}$, dengan ketinggian antena pemancar 24 meter. Dari hasil perhitungan didapatkan semakin jauh jarak antara antena pemancar terhadap penerima maka nilai pathloss semakin besar yaitu dari $138.8853 \mathrm{~dB}$ menjadi $175.4915 \mathrm{~dB}$. Sedangkan jika tinggi antena penerima diperbesar dengan jarak d antara eNodeB dengan MS tetap maka nilai pathloss menjadi menurun. Semakin besar nilai pathloss maka kualitas sinyal terima akan menurun demikian pula sebaliknya.

Kata Kunci: 4G LTE, pathloss, model propagasi COST 231

\section{PENDAHULUAN}

Perkembangan pesat teknologi komunikasi seluler dimulai dari generasi pertama (1G) sampai pada sekarang ini generasi keempat $(4 \mathrm{G})$ didasarkan kepada kebutuhan masyarakat akan informasi dan komunikasi yang menuntut tersedianya sistem komunikasi seluler yang bermutu tinggi. Dimana akan menjadi trend perubahan kebutuhan konsumen dari komunikai suara menjadi komunikasi data dengan kecepatan transfer yang semakin tinggi.

Teknologi 4G Long Term Evolution (LTE) dikembangkan dari suatu Third Generation Patnership Project (3GPP) yang merupakan pengembangan dari teknologi sebelumnya $3 \mathrm{G}$ 
(UMTS) yang memiliki kecepatan transfer rate 2 Mbps, dan 3,5 G (HSPA) yang mencapai 14 Mbps. LTE ini dirancang untuk memiliki kemampuan kecepatan transfer rate mencapai 100 Mbps pada sisi downlink dan 50 Mbps pada sisi uplink.

Dalam perencanaan jaringan telekomunikasi seluler termasuk 4G LTE, pada daerah urban, sub urban ataupun rural berbeda karena sinyal akan mengalami pantulan (reflected) yang berbeda disebabkan tingkat kepadatan rumah atau gedung yang berbeda. Banyaknya pantulan disepanjang saluran yang dilalui oleh sinyal akan menimbulkan redaman atau daya yang hilang disepanjang saluran atau yang lebih dikenal dengan istilah pathloss yang mempengaruhi kualitas sinyal. Oleh sebab itu perhitungan pathloss sangat penting dilakukan dalam perencanaan sebuah jaringan telekomunikasi.

\section{LANDASAN TEORI}

\section{A. Teknologi $4 G$ LTE}

Long Term Evolution (LTE) dikembangkan oleh Third Generation Patnership Project (3GPP) untuk memperbaiki teknologi sebelumnya yaitu $3 \mathrm{G}$ dan 3,5 G. Spesifikasi LTE ditargetkan untuk melayani downlink sedikitnya 100 Mbps dan uplink 50 Mbps. Gambar konfigurasi jaringan LTE sebagai berikut:

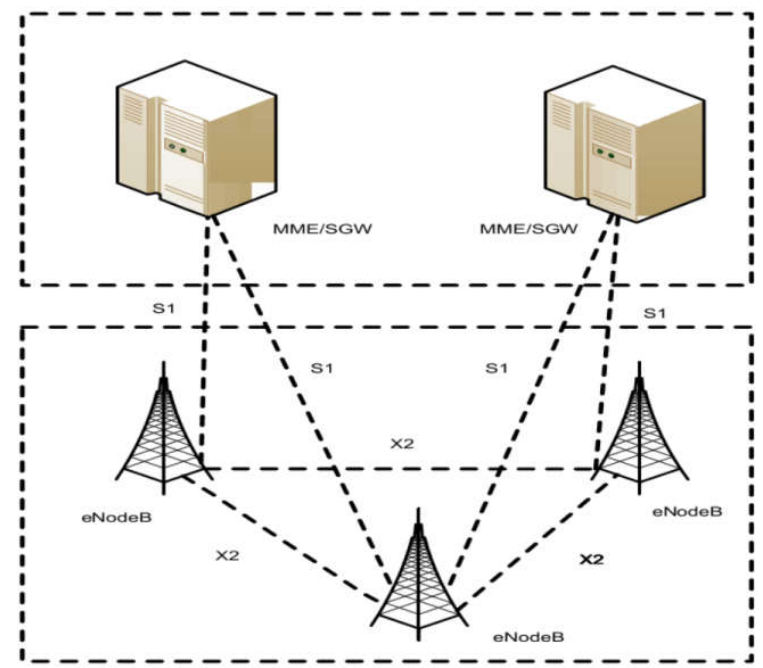

Gambar 1. Arsitektur Jaringan LTE
Keterangan gambar adalah sebagai berikut :

1. eNodeB

Jaringan akses pada LTE terdiri dari satu elemen, yaitu eNodeB. eNodeB (eNB) merupakan interface dengan UE (User Equipment). eNodeB berfungsi untuk Radio Resurce Management (RRM) dan sebagai transceiver. Sebagai RRM, fungsi eNodeB adalah untuk mengontrol dan mengawasi pengiriman sinyal yang dibawa oleh sinyal radio, berperan dalam autentikasi atau mengontrol kelayakan data yang akan melewati eNodeB, dan untuk mengatur scheduling.

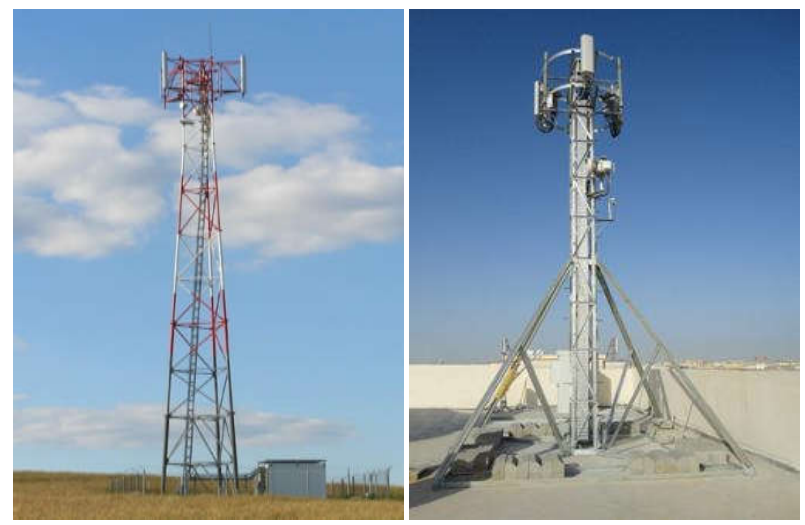

Gambar 2. eNode B

\section{Mobility Management Entity (MME)}

MME dapat dianalogikan sebagai MSC pada jaringan GSM. MME adalah node kontrol utama pada jaringan akses LTE. Ia bertanggung jawab untuk prosedur paging untuk idle mode UE termasuk retransmisi. MME juga bertanggung jawab dalam prosesaktivasi/ deaktivasi dan autentikasi user (dengan bantuan HSS). MME juga berfungsi untuk mengatur handover, yaitu memilih MME lain untuk handover dengan MME lain, atau memilih SGSN untuk handover dengan jaringan akses $2 \mathrm{G} / 3 \mathrm{G}$.

\section{Serving Gateway (SGW)}

SGW terdiri dari dua bagian, yaitu 3GPP Anchor dan SAE Anchor. 3GPP Anchor berfungsi sebagai gateway paket data yang berasal dari jaringan 3GPP, sedangkan SAE Anchor berfungsi sebagai gateway jaringan non3GPP. SGW merutekan dan memforward paket data user, sambil juga berfungsi sebagai mobility anchor saat handover antar eNodeB 
dan untukmenghubungkan LTE dengan jaringan lain yang sudah ada.

\section{Home Subscriber Server (HSS)}

HSS adalah database utama yang ada pada jaringan LTE. HSS adalah sebuah super HLR yang mengkombinasikan fungsi HLR sebagai database dan AuC sebagai autentikasi.

\section{B. Perambatan Gelombang Radio}

Propagasi adalah suatu metode proses perambatan gelombang radio dari pemancar $(T x)$ ke penerima $(R x)$ dan media transmisi sinyal yang digunakan adalah dengan media non-kawat (unguided) serta, memerlukan antena untuk meradiasikan sinyalnya ke udara bebas dan bentuk sinyal yang dipancarkan oleh pemancar adalah berupa gelombang sinyal elektromagnetik. Gelombang elektromagnetik ini akan merambat melalui udara bebas menuju antena penerima dan sinyal yang ditransmisikan oleh pemancar tersebut akan mengalami peredaman sepanjang lintasan yang dilaluinya, sehingga ketika sampai di antena penerima, energi sinyal sudah sangat lemah. Gelombang dalam perambatannya menuju antena penerima dapat melalui berbagai macam lintasan. Jenis lintasan yang diambil tergantung dari frekuensi sinyal, kondisi atmosfir dan waktu pentransmisian sinyal.

\section{Mekanisme Propagasi Gelombang}

Mekanisme propagsi gelombang elektromagnetik dalam sistem komunikasi wireless atau tanpa kabel memiliki tiga jenis yaitu :

1. Reflection adalah pantulan atau yang dikenal dengan (refleks) yang berlangsung ketika gelombang elektromagnetik mengenai objek yang memiliki dimensi jauh lebih besar dari panjang gelombang yang dipancarkan dan pantulan dapat terjadi pada permukaan tanah gedung serta tembok, contoh : Permukaan bumi, bangunan dan dinding.

2. Diffraction adalah penguraian sinyal (difraksi yang) berlangsung ketika radio $T x$ dan $R x$ bertabrakan atau dibelokan oleh benda yang memiliki sisi ujung lintasan yang tajam (sharp edge). Gelombanggelombang yang dihasilkan dari difraksi ini juga akan mmepengaruhi gelombang yang akan diterima meskipun bentuk halangan tidak terlihat secara langsung. Pada frekuensi tinggi difraksi sangat bergantung dengan bentuk objek.

3. Scattering adalah hamburan sinyal yang terjadi ketika saat sinyal mengenai objek yang mempunyai dimensi lebih kecil dibandingkan panjang gelombang sinyal sehingga menyebabkan energi menyebar kesegala arah. Hamburan dihasilkan oleh permukaan yang kasar, benda kecil, atau dapat disebabkan oleh ketidak teraturan dalam saluran frekuensi.

\section{PathLoss}

Path Loss/loss adalah (melemah/hilangnya) kekuatan daya sinyal informasi yang dipancarkan oleh antena pengirim sinyal $(T x)$ menuju penerima $(R x)$ yang berlangsung selama data/sinyal melewati media udara dan terjadi selama proses transmisi sinyal berlangsung dari antena pengirim menujupenerima dalam jarak tertentu. Nilai pathloss menunjukkan level sinyal yang melemah akibat mengalami (attenuation) yang disebabkan oleh propagasi ruang bebas/outdoor (free space) seperti pantulan/bayangan atau di kenal dengan refleksi, penguraian sinyal (difraksi) dan hamburan sinyal (Scatering).

Pathloss dapat timbul karena disebabkan oleh banyak faktor, seperti kontur tanah, lingkungan yang berbeda, medium propagasi (udara yang kering atau lembab), jarak antara antena pemancar (Tx) dengan penerima $(R x)$. Faktor-faktor yang mempengaruhi nilai level daya dan pathloss adalah jarak pengukuran antara $(T x)$ dan $(R x)$, tinggi antena (Tx dan $R x$ ), serta jenis area pengukuran yang digunakan.

\section{E. Model Propagasi COST 231}

Model propagasi jenis ini untuk mengestimasi pathloss di daerah urban dan beroperasi pada range frekuensi $1500 \mathrm{MHz}-$ $2000 \mathrm{MHz}$. 
Karakteristik model propagasi COST 231:

- $\quad$ Range frekuensi : $1500-2000 \mathrm{MHz}$

- $\mathrm{B}_{\mathrm{S}}\left(\mathrm{h}_{\mathrm{te}}\right): 30-200 \mathrm{~m}$ (Tinggi efektif antena transmiter)

- $\mathrm{M}_{\mathrm{S}}\left(\mathrm{h}_{\mathrm{re}}\right): 1-10 \mathrm{~m}$ (Tinggi efektif antena receiver)

- $\mathrm{d}: 1-20 \mathrm{Km} \mathrm{(Jarak} \mathrm{Bs-Ms)}$

a $\left(\mathrm{h}_{\mathrm{re}}\right)$ : adalah faktor koreksi untuk tinggi antena MS yang tergantung ukuran coverage area

Untuk daerah kecil :

$a\left(h_{r e}\right)=\left(1,1 \log F_{c}-0,7\right) h_{r e}-\left(1,56 \log f_{c}-0,8\right)$

Untuk daerah luas :

$a\left(h_{\text {re }}\right)=\left(8,29\left(\log 1,54 h_{\text {re }}\right)^{2}-1,1\right), f_{c} \geq 300 \mathrm{Mhz}$

$a\left(h_{r e}\right)=\left(3,2\left(\log 11,75 h_{r e}\right)^{2}-4,97\right), f_{c} \leq 300 \mathrm{Mhz}$

Untuk model propagasi jenis COST 231 dapat menggunakan persamaan :

$L($ urban $)=46,3+33,9 \log f_{c}-13,82 \log h_{t e}-a\left(h_{r e}\right)$

$+\left(44,9-6,55 \operatorname{logh} h_{t e}\right) \log d+C M$

- Nilai $\mathrm{CM} \longrightarrow$ untuk daerah small dan medium city $=0 \mathrm{~dB}$

- Nilai $\mathrm{CM} \longrightarrow$ untuk daerah large city (metropolitan center) $=3 \mathrm{~dB}$

\section{F. Klasifikasi Daerah}

Berdasarkan keberadaan penghalang dan tingkat kepadatan (obstacle) suatu halangan yang dapat menggangu proses pentransmisian yang berlangsung maka daerah dibagi menjadi tiga yaitu:

\section{Daerah Urban}

Adalah daerah wilayah yang dipadati penduduk dengan bangunan-bangunan besar dan memiliki gedung-gedung yang rapat serta tinggi misalnya daerah pusat kota baik metropolis maupun kota menengah dan memiliki ciri-ciri:

a. Gedung- gedung yang terdapat didaerah tersebut terbuat dari kerangka logam dan dindingnya terbuat dari beton yang tebal yang mengakibatkan pembatasan terhadap propagasi radio yang melalui jalur tersebut.

b. Karena gedung-gedung bangunan yang tinggi sehingga menyebabkan kemungkinan terjadinya penguraian sinyal (difraksi) pada propagasi sinyal sangat kecil.

c. Sinyal radio dalam perambatannya mengalami pantulan dengan redaman tertentu.

d. Redaman oleh pepohonan (foliage loss) diabaikan karena pepohonan yang sangat jarang.

e. Karena daerah urban adalah daerah yang padat penduduk maka tentunya pada daerah ini tingkat kendaraan pun akan semakin meningkat dan kendaraan yang bergerak dalam jumlah yang banyak dpat menyebabkan karakteristik kanal secara kontinyu.

\section{Daerah Sub Urban}

Adalah kategori daerah yang memiliki jumlah bangunan yang mulai padat dan tinggi rata-rata bangunan antara $12-20 \mathrm{~m}$ dan lebar 18-30m. Contoh: pinggiran kota dan kota- kota kecil. Daerah sub urban memiliki ciri-ciri antara lain:

- Tingkat halangan (obstacle) lebih rendah disbanding daerah urban sehingga propagasi sinyal radio relative lebih baik dan median kuat sinyal tinggi.

- Gedung-gedung bangunannya realtif rendah sehingga propagasi mengalami difraksi oleh puncak gedung.

- Pada jalan raya tidak terlalu padat oleh pengguna kendaraan.

- Kecepatan pergerakan kendaraan lebih cepat dibandingkan daerah urban.

- Daerah bisnis masih trgolong rendah

- Pembangunan infrasrtuktur baru masih terus dilakukan.

3. Daerah Rural

Adalah kategori jenis wilayah yang memiliki jumlah bangunan sedikit dan jarang atau dapat berupa alam terbuka misalnya pedesaan pada jenis lintasan propagasi ini memiliki sedikit penghalang (obstacle), daerah 
bebas sepanjang 300 - $400 \mathrm{~m}$ (tanah pertanian, ladang-ladang, dan lapangan terbuka). Adapun ciri -ciri daerah rural antara lain:

- Daerah sinyal yang diterima lebih besar dibandingkan dengan daerah urban dan $s u b$ urban karena jumlah penghalang yang sedikit.

- Memiliki ruas jalan yang lebar

- Lalu lintas pergerakan kendaraan tinggi karena sedikitnya jumlah pengendara.

\section{PEMODELAN SISTEM}

\section{A. Tahapan Penelitian}

Untuk tahapan penelitian antara lain:

1. Menentukan frekuensi LTE yang akan diteliti

2. Menentukan area eNode B

3. Menghitung nilai a(hre) untuk masingmasing daerah layanan

4. Menghitung pathloss untuk masing-masing daerah layanan

\section{B. Diagram Alir Penelitian}

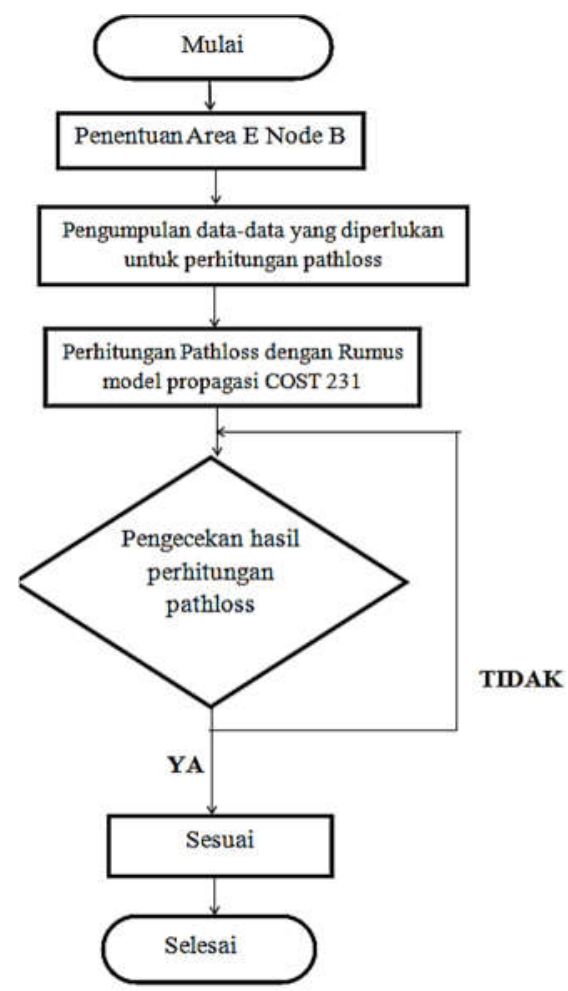

Gambar 3. Diagram Alir Penelitian

\section{ANALISA DAN HASIL}

Pada pembahasan ini data yang digunakan adalah data yang telah diperoleh dari PT. Indosat Ooredoo yaitu teknologi $4 \mathrm{G}$, frekuensi $1800 \mathrm{MHz}$ pada sampel kategori wilayah kota Balikpapan antara lain:

e Node B Lokasi daerah Jenderal Sudirman, Bs $\left(\mathrm{h}_{\mathrm{te}}\right)=24 \mathrm{~m}$

Dalam melakukan perhitungan pathloss pada penelitian ini penulis menggunakan beberapa variasi dari tinggi antena penerima $\mathrm{M}_{\mathrm{S}}$ $\left(\mathrm{h}_{\mathrm{re}}\right)$ dan jarak d (Jarak Bs - Ms)

Tabel 1. Variasi Parameter Perhitungan Pathloss

\begin{tabular}{|c|c|c|}
\hline No & $\begin{array}{c}\text { Tinggi antena } \\
\text { MS, } \mathrm{h}_{\text {re }} \text { (meter) }\end{array}$ & Jarak, d (km) \\
\hline 1 & 1 & $1,5,10,15,20$ \\
\hline 2 & 2 & $1,5,10,15,20$ \\
\hline 3 & 3 & $1,5,10,15,20$ \\
\hline 4 & 4 & $1,5,10,15,20$ \\
\hline 5 & 5 & $1,5,10,15,20$ \\
\hline 6 & 6 & $1,5,10,15,20$ \\
\hline 7 & 7 & $1,5,10,15,20$ \\
\hline 8 & 8 & $1,5,10,15,20$ \\
\hline 9 & 9 & $1,5,10,15,20$ \\
\hline 10 & 10 & $1,5,10,15,20$ \\
\hline
\end{tabular}

A. Perhitungan Pathloss $4 G$ LTE

1. Perhitungan Pathloss 4G LTE untuk MS $\left(\mathrm{h}_{\mathrm{re}}\right) 1$ meter

- Untuk melakukan perhitungan Pathloss 4G LTE untuk MS $\left(\mathrm{h}_{\mathrm{re}}\right) 1$ meter

- Frekuensi=1800 MHz (Frekuensi 4G LTE)

- $\quad \mathrm{Bs}\left(t_{t}\right)=24 \mathrm{~m}$ (Tinggi antena e node B)

- $\operatorname{Ms}\left(\begin{array}{c}r e \\ r e\end{array}\right)=1 \quad$ (Tinggi antena MS )

- $\mathrm{d}=1 \mathrm{~km}$ (Jarak Bs- Ms)

a $\left(\mathrm{h}_{\mathrm{re}}\right)$ : adalah faktor koreksi untuk tinggi antena MS yang tergantung ukuran coverage area. Untuk penelitian ini diambil nilai a $\left(\mathrm{h}_{\mathrm{re}}\right)$ untuk daerah luas

- Nilai CM $=0 \mathrm{~dB}$, daerah small dan medium city 


$$
\text { a } \begin{aligned}
\left(\mathbf{h}_{\mathbf{r e}}\right) & =\left(\mathbf{3 , 2}\left(\log \mathbf{1 1 , 7 5} \mathbf{h}_{\mathbf{r e}}\right)^{\mathbf{2}}-\mathbf{4 , 9 7}\right) \\
& =\left(3,2(\log 11,75.1)^{2}-4,97\right) \\
& =-1.306060685
\end{aligned}
$$

Untuk model propagasi COST 231 maka pengukuran pathloss dilakukan untuk area urban dapat menggunakan persamaan :

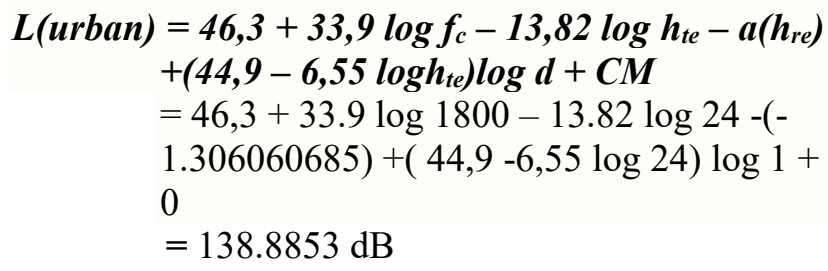

Untuk perhitungan pathloss 4G LTE MS $\left(\mathrm{h}_{\mathrm{re}}\right) 1$ meter dengan variasi $\mathrm{d}=1 \mathrm{~km}, 5 \mathrm{~km}, 10$ $\mathrm{km}, 15 \mathrm{~km}, 20 \mathrm{~km}$ diberikan pada tabel berikut:

Tabel 2. Perhitungan Pathloss 4G LTE MS ( $\left.\mathrm{h}_{\mathrm{re}}\right) 1$ meter

\begin{tabular}{|c|c|c|c|}
\hline No & $\begin{array}{c}\text { Tinggi } \\
\text { antena MS, } \\
\mathbf{h}_{\text {re }} \text { (meter) }\end{array}$ & $\begin{array}{c}\text { Jarak, } \\
\mathbf{d}(\mathbf{k m})\end{array}$ & $\begin{array}{c}\text { Pathloss } \\
\mathbf{( d B})\end{array}$ \\
\hline 1 & 1 & 1 & 138.8853 \\
\hline 2 & 1 & 5 & 163.9501 \\
\hline 3 & 1 & 10 & 174.7449 \\
\hline 4 & 1 & 15 & 181.0595 \\
\hline 5 & 1 & 20 & 185.5397 \\
\hline
\end{tabular}

2. Perhitungan Pathloss 4G LTE untuk MS $\left(\mathrm{h}_{\mathrm{re}}\right) 2$ meter

Untuk perhitungan pathloss 4G LTE MS $\left(\mathrm{h}_{\mathrm{re}}\right) 2$ meter dengan variasi $\mathrm{d}=1 \mathrm{~km}, 5 \mathrm{~km}, 10$ $\mathrm{km}, 15 \mathrm{~km}, 20 \mathrm{~km}$ diberikan pada tabel berikut:

Tabel 3. Perhitungan Pathloss 4G LTE MS $\left(\mathrm{h}_{\mathrm{re}}\right) 2$ meter

\begin{tabular}{|c|c|c|c|}
\hline No. & $\begin{array}{c}\text { Tinggi } \\
\text { antena MS, } \\
\mathbf{h}_{\text {re }}(\mathbf{m e t e r})\end{array}$ & $\begin{array}{c}\text { Jarak, } \\
\mathbf{d}(\mathbf{k m})\end{array}$ & $\begin{array}{c}\text { Pathloss } \\
\mathbf{( d B})\end{array}$ \\
\hline 1 & 2 & 1 & 136.5338 \\
\hline 2 & 2 & 5 & 161.5986 \\
\hline 3 & 2 & 10 & 172.3934 \\
\hline 4 & 2 & 15 & 178.708 \\
\hline 5 & 2 & 20 & 183.1882 \\
\hline
\end{tabular}

untuk $f_{c} \geq 300 \mathrm{Mhz}$

3. Perhitungan Pathloss 4G LTE untuk MS $\left(h_{\mathrm{re}}\right) 3$ meter

Untuk perhitungan pathloss 4G LTE MS ( $\left.\mathrm{h}_{\mathrm{re}}\right) 3$ meter dengan variasi $\mathrm{d}=1 \mathrm{~km}, 5 \mathrm{~km}, 10$ $\mathrm{km}, 15 \mathrm{~km}, 20 \mathrm{~km}$ diberikan pada tabel berikut:

Tabel 4. Perhitungan Pathloss 4G LTE MS $\left(\left(\mathrm{h}_{\mathrm{re}}\right) 3\right.$ meter

\begin{tabular}{|c|c|c|c|}
\hline No. & $\begin{array}{c}\text { Tinggi antena } \\
\text { MS, hre } \\
\text { (meter) }\end{array}$ & $\begin{array}{c}\text { Jarak, } \\
\mathbf{d}(\mathbf{k m})\end{array}$ & $\begin{array}{c}\text { Pathloss } \\
\mathbf{( d B )}\end{array}$ \\
\hline 1 & 3 & 1 & 134.8894 \\
\hline 2 & 3 & 5 & 159.9542 \\
\hline 3 & 3 & 10 & 170.749 \\
\hline 4 & 3 & 15 & 177.0636 \\
\hline 5 & 3 & 20 & 181.5438 \\
\hline
\end{tabular}

4. Perhitungan Pathloss 4G LTE untuk MS (hre) 4 meter

Untuk perhitungan pathloss 4G LTE MS ( $\left.\mathrm{h}_{\mathrm{re}}\right) 4$ meter dengan variasi $\mathrm{d}=1 \mathrm{~km}, 5 \mathrm{~km}, 10$ $\mathrm{km}, 15 \mathrm{~km}, 20 \mathrm{~km}$ diberikan pada tabel berikut:

Tabel 5. Perhitungan Pathloss 4G LTE MS $\left(\mathrm{h}_{\text {re }}\right) 4$ meter

\begin{tabular}{|c|c|c|c|}
\hline No. & $\begin{array}{c}\text { Tinggi antena } \\
\text { MS, } \mathbf{h}_{\text {re }} \text { (meter) }\end{array}$ & $\begin{array}{c}\text { Jarak, } \\
\mathbf{d}(\mathbf{k m})\end{array}$ & $\begin{array}{c}\text { Pathloss } \\
\mathbf{( d B})\end{array}$ \\
\hline 1 & 4 & 1 & 133.6023 \\
\hline 2 & 4 & 5 & 158.6671 \\
\hline 3 & 4 & 10 & 169.4619 \\
\hline 4 & 4 & 15 & 175.7765 \\
\hline 5 & 4 & 20 & 180.2567 \\
\hline
\end{tabular}

5. Perhitungan Pathloss 4G LTE untuk MS (hre) 5 meter

Untuk perhitungan pathloss 4G LTE MS $\left(\left(\mathrm{h}_{\mathrm{re}}\right) 5\right.$ meter dengan variasi $\mathrm{d}=1 \mathrm{~km}, 5 \mathrm{~km}, 10$ $\mathrm{km}, 15 \mathrm{~km}, 20 \mathrm{~km}$ diberikan pada tabel berikut: 
Tabel 6. Perhitungan Pathloss 4G LTE MS ( $\left.\mathrm{h}_{\mathrm{re}}\right) 5$ meter

\begin{tabular}{|c|c|c|c|}
\hline No. & $\begin{array}{c}\text { Tinggi } \\
\text { antena } \\
\text { MS, } \mathbf{h}_{\mathbf{r e}} \\
\text { (meter) }\end{array}$ & $\begin{array}{c}\text { Jarak, } \\
\mathbf{d}(\mathbf{k m})\end{array}$ & Pathloss (dB) \\
\hline 1 & 5 & 1 & 132.5352 \\
\hline 2 & 5 & 5 & 157.6 \\
\hline 3 & 5 & 10 & 168.3948 \\
\hline 4 & 5 & 15 & 174.7094 \\
\hline 5 & 5 & 20 & 179.1896 \\
\hline
\end{tabular}

6. Perhitungan Pathloss 4G LTE untuk MS $\left(\mathrm{h}_{\mathrm{re}}\right) 6$ meter

Untuk perhitungan pathloss 4G LTE MS $\left(\mathrm{h}_{\mathrm{re}}\right) 6$ meter dengan variasi $\mathrm{d}=1 \mathrm{~km}, 5 \mathrm{~km}, 10$ $\mathrm{km}, 15 \mathrm{~km}, 20 \mathrm{~km}$ diberikan pada tabel berikut:

Tabel 7. Perhitungan Pathloss 4G LTE MS $\left(\mathrm{h}_{\mathrm{re}}\right) 6$ meter

\begin{tabular}{|c|c|c|c|}
\hline No. & $\begin{array}{c}\text { Tinggi antena } \\
\text { MS, } \mathbf{h}_{\mathbf{r e}} \\
\text { (meter) }\end{array}$ & $\begin{array}{c}\text { Jarak, } \\
\mathbf{d} \\
\mathbf{( k m )}\end{array}$ & $\begin{array}{c}\text { Pathloss } \\
\mathbf{( d B})\end{array}$ \\
\hline 1 & 6 & 1 & 131.6186 \\
\hline 2 & 6 & 5 & 156.6834 \\
\hline 3 & 6 & 10 & 167.4783 \\
\hline 4 & 6 & 15 & 173.7928 \\
\hline 5 & 6 & 20 & 178.2731 \\
\hline
\end{tabular}

7. Perhitungan Pathloss 4G LTE untuk MS $\left(\mathrm{h}_{\mathrm{re}}\right) 7$ meter

Untuk perhitungan pathloss 4G LTE MS $\left(\mathrm{h}_{\mathrm{re}}\right) 7$ meter dengan variasi $\mathrm{d}=1 \mathrm{~km}, 5 \mathrm{~km}, 10$ km, $15 \mathrm{~km}, 20 \mathrm{~km}$ diberikan pada tabel berikut:
Tabel 8. Perhitungan Pathloss 4G LTE MS $\left(\mathrm{h}_{\mathrm{re}}\right) 7$ meter

\begin{tabular}{|c|c|c|c|}
\hline No. & $\begin{array}{c}\text { Tinggi } \\
\text { antena } \\
\text { MS, } \mathbf{h}_{\mathbf{r e}} \\
\text { (meter) }\end{array}$ & $\begin{array}{c}\text { Jarak, } \\
\mathbf{d}(\mathbf{k m})\end{array}$ & Pathloss (dB) \\
\hline 1 & 7 & 1 & 130.8124 \\
\hline 2 & 7 & 5 & 155.8772 \\
\hline 3 & 7 & 10 & 166.672 \\
\hline 4 & 7 & 15 & 172.9866 \\
\hline 5 & 7 & 20 & 177.4669 \\
\hline
\end{tabular}

8. Perhitungan Pathloss 4G LTE untuk MS $\left(\mathrm{h}_{\mathrm{re}}\right) 8$ meter

Untuk perhitungan pathloss $4 \mathrm{G}$ LTE MS $\left(\mathrm{h}_{\mathrm{re}}\right) 8$ meter dengan variasi $\mathrm{d}=1 \mathrm{~km}, 5 \mathrm{~km}, 10$ $\mathrm{km}, 15 \mathrm{~km}, 20 \mathrm{~km}$ diberikan pada tabel berikut:

Tabel 9. Perhitungan Pathloss 4G LTE MS $\left(\mathrm{h}_{\mathrm{re}}\right) 8$ meter

\begin{tabular}{|c|c|c|c|}
\hline No. & $\begin{array}{c}\text { Tinggi } \\
\text { antena } \\
\text { MS, } \mathbf{h}_{\mathbf{r e}} \\
\text { (meter) }\end{array}$ & $\begin{array}{c}\text { Jarak, } \\
\mathbf{d} \\
\mathbf{( k m )}\end{array}$ & $\begin{array}{c}\text { Pathloss } \\
\mathbf{( d B )}\end{array}$ \\
\hline 1 & 8 & 1 & 130.0909 \\
\hline 2 & 8 & 5 & 155.1557 \\
\hline 3 & 8 & 10 & 165.9505 \\
\hline 4 & 8 & 15 & 172.2651 \\
\hline 5 & 8 & 20 & 176.7453 \\
\hline
\end{tabular}

9. Perhitungan Pathloss 4G LTE untuk MS $\left(\mathrm{h}_{\mathrm{re}}\right) 9$ meter

Untuk perhitungan pathloss 4G LTE MS $\left(\mathrm{h}_{\mathrm{re}}\right) 9$ meter dengan variasi $\mathrm{d}=1 \mathrm{~km}, 5 \mathrm{~km}, 10$ $\mathrm{km}, 15 \mathrm{~km}, 20 \mathrm{~km}$ diberikan pada tabel berikut: 
Tabel 10. Perhitungan Pathloss $4 \mathrm{G}$ LTE MS $\left(\mathrm{h}_{\mathrm{re}}\right) 9$ meter

\begin{tabular}{|c|c|c|c|}
\hline No. & $\begin{array}{l}\text { Tinggi } \\
\text { antena } \\
\text { MS, } \mathbf{h}_{\mathrm{re}} \\
\text { (meter) }\end{array}$ & $\begin{array}{l}\text { Jarak, } \\
\text { d (km) }\end{array}$ & $\begin{array}{c}\text { Pathloss } \\
\text { (dB) }\end{array}$ \\
\hline 1 & 9 & 1 & 129.4365 \\
\hline 2 & 9 & 5 & 154.5013 \\
\hline 3 & 9 & 10 & 165.2962 \\
\hline 4 & 9 & 15 & 171.6107 \\
\hline 5 & 9 & 20 & 176.091 \\
\hline
\end{tabular}

10. Perhitungan Pathloss 4G LTE untuk MS $\left(h_{r e}\right) 10$ meter

Untuk perhitungan pathloss 4G LTE MS $\left(\mathrm{h}_{\mathrm{re}}\right) 10$ meter dengan variasi $\mathrm{d}=1 \mathrm{~km}, 5 \mathrm{~km}, 10$ $\mathrm{km}, 15 \mathrm{~km}, 20 \mathrm{~km}$ diberikan pada tabel berikut:

Tabel 11. Perhitungan Pathloss 4 G LTE MS $\left(h_{\text {re }}\right)$ 10 meter

\begin{tabular}{|c|c|c|c|}
\hline No. & $\begin{array}{c}\text { Tinggi } \\
\text { antena MS, } \\
\mathbf{h}_{\text {re }} \text { (meter) }\end{array}$ & $\begin{array}{c}\text { Jarak, } \\
\mathbf{d}(\mathbf{k m})\end{array}$ & Pathloss (dB) \\
\hline 1 & 10 & 1 & 128.8337 \\
\hline 2 & 10 & 5 & 153.9018 \\
\hline 3 & 10 & 10 & 164.6967 \\
\hline 4 & 10 & 15 & 171.0112 \\
\hline 5 & 10 & 20 & 175.4915 \\
\hline
\end{tabular}

C. Perbandingan Pathloss dengan Nilai MS $\left(h_{r e}\right)$ yang Semakin Besar

1. Untuk nilai $\mathrm{d}=1 \mathrm{~km}, \mathrm{BS}$ hte $=24 \mathrm{~m}$, nilai MS hre dari $1 \mathrm{~m}-10 \mathrm{~m}$
Tabel 12. Perbandingan Pathloss $\mathrm{d}=1 \mathrm{~km}$, BS hte $=$ $24 \mathrm{~m}, \mathrm{MS}$ hre $1-10 \mathrm{~m}$

\begin{tabular}{|c|c|c|}
\hline \multirow{11}{*}{$\begin{array}{l}\mathrm{d}=1 \mathrm{~km}, \\
\mathrm{BS} \text { hte }=24 \\
\mathrm{~m},\end{array}$} & $\begin{array}{l}\text { MS, } h_{\text {re }} \\
\text { (meter) }\end{array}$ & $\begin{array}{l}\text { Pathloss } \\
\text { (dB) }\end{array}$ \\
\hline & 1 & 138.8853 \\
\hline & 2 & 136.5338 \\
\hline & 3 & 134.8894 \\
\hline & 4 & 133.6023 \\
\hline & 5 & 132.5352 \\
\hline & 6 & 131.6186 \\
\hline & 7 & 130.8124 \\
\hline & 8 & 130.0909 \\
\hline & 9 & 129.4365 \\
\hline & 10 & 128.837 \\
\hline
\end{tabular}

2. Untuk nilai $\mathrm{d}=5 \mathrm{~km}, \mathrm{BS}$ hte $=24 \mathrm{~m}$, nilai MS hre dari $1 \mathrm{~m}-10 \mathrm{~m}$

Tabel 13. Perbandingan Pathloss $d=5 \mathrm{~km}, \mathrm{BS}$ the $=$ $24 \mathrm{~m}, \mathrm{MS}$ hre $1-10 \mathrm{~m}$

\begin{tabular}{|l|c|c|}
\hline \multirow{1}{*}{} & $\begin{array}{c}\text { MS, } \\
\text { (meter) }\end{array}$ & $\begin{array}{c}\text { Pathloss } \\
\text { (dB) }\end{array}$ \\
\cline { 2 - 3 } & 1 & 163.9501 \\
\cline { 2 - 3 } $\mathrm{d}=5 \mathrm{~km}$, & 2 & 161.5986 \\
\cline { 2 - 3 } $\begin{array}{l}\text { BS hte }=24 \\
\text { m, }\end{array}$ & 3 & 159.9542 \\
\cline { 2 - 3 } & 4 & 158.6671 \\
\cline { 2 - 3 } & 5 & 157.6 \\
\cline { 2 - 3 } & 7 & 156.6834 \\
\cline { 2 - 3 } & 8 & 155.8772 \\
\cline { 2 - 3 } & 9 & 155.1557 \\
\cline { 2 - 3 } & 10 & 154.5013 \\
\hline
\end{tabular}

3. Untuk nilai $\mathrm{d}=10 \mathrm{~km}, \mathrm{BS}$ hte $=24 \mathrm{~m}$, nilai MS hre dari $1 \mathrm{~m}-10 \mathrm{~m}$

Tabel 14. Perbandingan Pathloss $\mathrm{d}=10 \mathrm{~km}, \mathrm{BS}$ the $=24 \mathrm{~m}$, MS hre $1-10 \mathrm{~m}$

\begin{tabular}{|l|c|c|}
\hline \multirow{5}{*}{} & $\begin{array}{c}\text { MS, } \\
\text { (meter) }\end{array}$ & $\begin{array}{c}\text { Pathloss } \\
\text { (dB) }\end{array}$ \\
\cline { 2 - 3 } & 1 & 174.7449 \\
\cline { 2 - 3 } & 2 & 172.3934 \\
\cline { 2 - 3 } d = 10 km, & 3 & 170.749 \\
\cline { 2 - 3 } BS hte $=$ & 4 & 169.4619 \\
\cline { 2 - 3 } $24 \mathrm{~m}$, & 5 & 168.3948 \\
\cline { 2 - 3 } & 6 & 167.4783 \\
\cline { 2 - 3 } & 7 & 166.672 \\
\cline { 2 - 3 } & 8 & 165.9505 \\
\cline { 2 - 3 } & 9 & 165.2962 \\
\cline { 2 - 3 } & 10 & 164.6967 \\
\hline
\end{tabular}


4. Untuk nilai $\mathrm{d}=15 \mathrm{~km}, \mathrm{BS}$ hte $=24 \mathrm{~m}$, nilai MS hre dari $1 \mathrm{~m}-10 \mathrm{~m}$

Tabel 15. Perbandingan Pathloss $\mathrm{d}=15 \mathrm{~km}$, BS the $=24 \mathrm{~m}$, MS hre $1-10 \mathrm{~m}$

\begin{tabular}{|l|c|c|}
\hline \multirow{4}{*}{$\begin{array}{l}\text { d }=15 \mathrm{~km}, \\
\text { BS hte }=24 \\
\mathrm{~m},\end{array}$} & $\begin{array}{c}\text { MS, } \mathbf{h}_{\text {re }} \\
\text { (meter) }\end{array}$ & Pathloss (dB) \\
\cline { 2 - 3 } & 1 & 181.0595 \\
\cline { 2 - 3 } & 2 & 178.708 \\
\cline { 2 - 3 } & 3 & 177.0636 \\
\cline { 2 - 3 } & 4 & 175.7765 \\
\cline { 2 - 3 } & 5 & 174.7094 \\
\cline { 2 - 3 } & 6 & 173.7928 \\
\cline { 2 - 3 } & 7 & 172.9866 \\
\cline { 2 - 3 } & 8 & 172.2651 \\
\cline { 2 - 3 } & 9 & 171.6107 \\
\hline
\end{tabular}

5. Untuk nilai $\mathrm{d}=20 \mathrm{~km}, \mathrm{BS}$ hte $=24 \mathrm{~m}$, nilai MS hre dari $1 \mathrm{~m}-10 \mathrm{~m}$

Tabel 16. Perbandingan Pathloss $\mathrm{d}=20 \mathrm{~km}$, BS the $=24 \mathrm{~m}$, MS hre $1-10 \mathrm{~m}$

\begin{tabular}{|l|c|c|}
\hline \multirow{4}{*}{} & $\begin{array}{c}\text { MS, hre } \\
\text { (meter) }\end{array}$ & $\begin{array}{c}\text { Pathloss } \\
\text { (dB) }\end{array}$ \\
\cline { 2 - 3 } & 1 & 185.5397 \\
\cline { 2 - 3 } $\mathrm{d}=20 \mathrm{~km}$, & 2 & 183.1882 \\
\cline { 2 - 3 } BS hte =24 & 3 & 181.5438 \\
\cline { 2 - 3 } m, & 4 & 180.2567 \\
\cline { 2 - 3 } & 5 & 179.1896 \\
\cline { 2 - 3 } & 6 & 178.2731 \\
\cline { 2 - 3 } & 7 & 177.4669 \\
\cline { 2 - 3 } & 8 & 176.7453 \\
\cline { 2 - 3 } & 9 & 176.091 \\
\hline
\end{tabular}

\section{KESIMPULAN}

Dari hasil perhitungan pathlosss dan analisa yang telah dilakukan maka didapatkan beberapa kesimpulan sebagai berikut :

1. Semakin jauh jarak antara Mobile Station (MS) terhadap e Node B maka semakin besar pathloss yang terjadi yaitu dari $138.8853 \mathrm{~dB}$ sampai $175.4915 \mathrm{~dB}$

2. Penambahan tinggi antena di sisi penerima (MS) dengan jarak d yang tetap $(\mathrm{d}=1 \mathrm{~km})$ akan membuat nilai pathloss akan mengalami penurunan yaitu $138.8853 \mathrm{~dB}$ menjadi $128.837 \mathrm{~dB}$

3. Penambahan tinggi antena di sisi penerima (MS) dengan jarak d yang tetap $(\mathrm{d}=5 \mathrm{~km})$ akan membuat nilai pathloss akan mengalami penurunan yaitu $163.9501 \mathrm{~dB}$ menjadi $153.9018 \mathrm{~dB}$

4. Penambahan tinggi antena di sisi penerima (MS) dengan jarak d yang tetap $(\mathrm{d}=10 \mathrm{~km})$ akan membuat nilai pathloss akan mengalami penurunan yaitu $174.7449 \mathrm{~dB}$ menjadi $164.6967 \mathrm{~dB}$

5. Penambahan tinggi antena di sisi penerima (MS) dengan jarak d yang tetap $(\mathrm{d}=15 \mathrm{~km})$ akan membuat nilai pathloss akan mengalami penurunan yaitu $181.0595 \mathrm{~dB}$ menjadi $171.0112 \mathrm{~dB}$

6. Penambahan tinggi antena di sisi penerima (MS) dengan jarak d yang tetap $(\mathrm{d}=20 \mathrm{~km})$ akan membuat nilai pathloss akan mengalami penurunan yaitu $185.5397 \mathrm{~dB}$ menjadi $175.4915 \mathrm{Db}$

\section{REFERENSI}

[1] Kurniawan, Uke. "Fudamental Teknologi Seluler LTE”, Rekayasa Sains, 2012

[2] Kurniawan, Uke. "Pengantar Telekomunikasi", Informatika, 2010

[3] Rappaport, Theodor S., "Wireless Communcation Principles and Practice", Prentice Hall, 1996.

[4] Sari, Nilam.2016, "Tugas Akhir : Analisa Perhitungan Pathloss Sinyal Node B daerah Urban, Sub Urban, Rural Kota Balikpapan", Jurusan Teknik Elektronika, Politeknik Negeri Balikpapan

[5] Wibisono, Kurniawan. "Konsep Teknologi Seluer”, Informatika, 2008 